\title{
Análise do deslocamento pendular para o trabalho do município de Colombo para Curitiba (PR)
}

\author{
Gislene Santos*
}

Os dados censitários do IBGE (2000) revelaram que 7,4 milhões de pessoas no Brasil se dirigiram para outro município que não o de sua residência, para trabalhar e/ou estudar. Análise recente (DESCHAMPS, M.; CINTRA, A., 2007) demarca a posição do Estado do Paraná no contexto dos fluxos pendulares: cerca de 435.309 pessoas estavam diretamente envolvidas no deslocamento pendular. Desse total, $86 \%$ do fluxo circulava dentro do próprio Estado, 10\% em outra unidade da Federação e $4 \%$ deslocava-se para outros países. ${ }^{1}$ o que desperta atenção, e é objeto deste ensaio, é que dos dez principais municípios paranaenses que enviavam, diariamente, população para fora de sua unidade administrativa, Colombo, integrante da Região Metropolitana de Curitiba (RMC), ocupasse o 1. - lugar, com o significativo número de 40 mil pessoas que se deslocavam para Curitiba, com o objetivo de trabalhar ou estudar.

Não é nenhuma novidade que os deslocamentos pendulares constituem um dos elementos das dinâmicas territoriais que revelam e caracterizam a extensão da urbanização. Entretanto, no Brasil, há poucos estudos teóricos e parca divulgação dos dados estatísticos oficiais (IBGE) sobre esse tipo de deslocamento. Uma análise mais precisa dessa dinâmica, em escalas espaciais particulares, possibilita entender uma das questões fundamentais do Brasil contemporâneo: a mobilidade laboral entre as cidades.

Para entender essa dinâmica na RMC, utilizo um conjunto de dados estatísticodemográficos (Censo 2000, IBGE) sobre a intensidade e a direção do fluxo pendular originado no município de Colombo. ${ }^{2}$ Para complementá-los, auxilio-me de

\footnotetext{
* Gislene Santos é Geógrafa, Docente do Dpto. de Geografia da Universidade Federal do Paraná. Integrante do projeto "Território, Coesão Social e Governança Democrática", Linha de Pesquisa: Metropolização, Dinâmicas Intrametropolitanas e o Território Nacional. Instituto do Milênio$\mathrm{CNPq/Observatório} \mathrm{das} \mathrm{Metrópoles.}$
} 
entrevistas realizadas em Curitiba com trabalhadores pendulares de Colombo. ${ }^{3}$ Busco assim mediação metodológica entre um viés quantitativo e outro qualitativo. Para consenso entre as duas fontes de informação, entrevistei pessoas que se deslocam, regularmente, cinco dias por semana de Colombo em direção a Curitiba para trabalhar. Esse recorte temporal (fluxo diário) segue o conceito de deslocamento pendular dado pelo IBGE, como "deslocamento diário da casa para o trabalho ou local de estudo". (IBGE: 2004, p.42). (grifo meu)

Convém salientar, já de início, que se trata de um universo de pessoas que saem diariamente do seu município de residência para o trabalho - desconsidero aqui aqueles que somente estudam. O critério de seleção dos entrevistados restringiu-se à categoria dos trabalhadores por reconhecer, como ensinam Polanyi (2000) e Foucault (2008), que é o trabalho que cria a condição social, econômica e política da mobilidade da população.

Na primeira seção, o foco é dirigido para o processo de incorporação de Colombo a uma dinâmica populacional intrinsecamente conectada à urbanização de Curitiba. Escalas explicativas, como a migração interna no Brasil nos anos de 1960, o processo de modernização agrícola paranaense e a migração rural-urbana, são algumas das variáveis invocadas para explicar a dinâmica do adensamento populacional em Colombo e sua singular participação no deslocamento pendular. Em seguida, na segunda seção, são descritas as características do deslocamento: direção, intensidade e ocupação dos pendulares, em Curitiba, por grupos de atividades.

Através desse duplo exercício, pretende-se refletir sobre o território na escala urbana, embora não se trate de exaustivo estudo de caso, nem de um inventário de elementos locais. Focalizando essa particularidade, busco compreender o lugar do trabalho na economia metropolitana paranaense e as tensões impressas no território, evidenciadas por esse tipo de deslocamento.

\section{A dinâmica da periferização na Região Metropolitana de Curitiba}

Quem andou pelas ruas centrais de Colombo, durante o período natalino de 2007, deparou-se com os seguintes slogans, expostos em alguns estabelecimentos comerciais: "Quem ama Colombo compra em Colombo" e "Gaste aqui o seu 13.o salário", entre outros.

Localizado na porção norte da capital metropolitana, Colombo é um dos 26 municípios integrantes da RMC. Aferição na planta da cidade de Colombo (2000) demonstra a extensão da mancha urbana em direção a Curitiba, Pinhais, Campina Grande do Sul, Quatro Barras e Almirante Tamandaré. Desde os anos 1980, das rodovias estaduais, à progressiva implantação dos contornos Norte e Sul, até as políticas de transporte público integrado e programas de acessibilidade, os municípios ao entorno de Curitiba se inseriram numa extensa rede de circulação viária que os conectaram à metrópole. Esses "sistemas de engenharia", para usar uma expressão do geógrafo Milton Santos, provocaram uma configuração territorial 
que facultou a constituição de novas paisagens urbanas e econômicas a partir dos anos 1980. Desse conjunto de ações coordenadas, o intenso deslocamento pendular de Colombo a Curitiba, ora analisado, não se inscreve, portanto, num território virgem, vazio de ações. Ao contrário, nele foi implantada uma gama de objetos para permitir a circulação de bens, pessoas e mercadorias.

Assim, a distância entre os municípios adjacentes ao norte de Curitiba se encurta. Em Colombo, dos bairros Jardim Osasco, Maracanã e Jardim Rio Verde, chega-se à área central de Curitiba em aproximadamente 20 minutos. A distância desses mesmos bairros à área central de Colombo é próxima à de Curitiba (10 $\mathrm{km})$; entretanto, a oferta de serviços, especialmente do setor doméstico, e instituições de ensino superior encontra-se em Curitiba, o que leva $22 \%$ de sua população total a deslocar-se diariamente para esta última, para trabalhar e/ou estudar. Cerca de 65 mil pessoas utilizam diariamente os serviços de transporte intraurbano no Terminal Alto Maracanã - de madrugada, por volta das 5 horas da manhã, inicia-se o tumultuado movimento de passageiros que tomam o ônibus em direção a Curitiba. ${ }^{4}$

No interior da RMC, segundo Deschamps e Cintra (2008), 194 mil pessoas, em 2000, movimentavam-se para trabalhar e/ou estudar, e $80 \%$ desse total se dirigia a Curitiba. O maior fluxo de pessoas era representado por Colombo (39.950), Pinhais (23.804), São José dos Pinhais (22.989) e Almirante Tamandaré (22.568). O fluxo de Colombo espalhava-se por 14 municípios da RMC, mas estava centralizado em Curitiba (tabela 1).

Tabela 1 - Principais municípios de destino para trabalho e/ou estudo de pessoas provenientes do Colombo - 2000

\begin{tabular}{|l|c|}
\hline MUNICÍPIOS DE DESTINO & PESSOAS \\
\hline Almirante Tamandaré & 152 \\
Araucária & 175 \\
Bocaiúva do Sul & 47 \\
Campina Grande do Sul & 292 \\
Campo Largo & 58 \\
Curitiba & 37.056 \\
Fazenda Rio Grande & 31 \\
Lapa & 10 \\
Pinhais & 1.128 \\
Piraquara & 116 \\
Quatro Barras & 373 \\
Rio Branco do Sul & 9 \\
São José dos Pinhais & 488 \\
Tunas do Paraná & 15 \\
\hline TOTAL & 39.950 \\
\hline
\end{tabular}

FONTE: DESCHAMPS; CINTRA (2008) 
Nesse contexto, faz sentido a propaganda do setor comercial que traduz a preocupação em atrair sua população para o comércio local. Entrevistas realizadas com trabalhadores provenientes de Colombo revelam certa regularidade nas suas informações sobre a preferência de comprar aparelhos eletrodomésticos e alimentos em lojas e supermercados de Curitiba, visto que passam ali grande parte do seu tempo diário. "Minha vida é toda aqui praticamente, eu só moro (durmo) em Colombo. (...) Em Curitiba compro eletrodomésticos, e a compra do supermercado é feita no Bairro Santa Cândida".

Em levantamento de campo, Katzinsky (2004) constata que as relações de consumo e lazer dos moradores do bairro Maracanã com a sede de Colombo são diminutas. As maiores trocas comerciais e o uso do tempo do lazer se realizam no próprio bairro ou, então, em Curitiba.

Colombo, como já assinalado, apresenta uma contribuição ímpar no fluxo pendular paranaense. No ano de 2000 , o número de pessoas envolvidas mais do que triplicou em relação aos anos 1980.

Tabela 2 - fluxos pendulares no Paraná: principais municípios de origem 1980 e 2000

\begin{tabular}{|l|c|l|c|}
\hline \multicolumn{1}{|c|}{$\begin{array}{c}\text { MUNICÍPIO DE } \\
\text { ORIGEM (1980) }\end{array}$} & $\begin{array}{c}\text { PESSOAS } \\
\text { ENVOLVIDAS }\end{array}$ & \multicolumn{1}{|c|}{$\begin{array}{l}\text { MUNICÍPIO DE } \\
\text { ORIGEM (2000) }\end{array}$} & $\begin{array}{c}\text { PESSOAS } \\
\text { ENVOLVIDAS }\end{array}$ \\
\hline Piraquara & 13.991 & Colombo & 40.182 \\
Colombo & 12.926 & Pinhais & 23.934 \\
Curitiba & 7.065 & São José dos Pinhais & 23.262 \\
Cambé & 6.396 & Almirante Tamandaré & 22.715 \\
Almirante Tamandaré & 6.200 & Curitiba & 21.399 \\
São José dos Pinhais & 5.480 & Piraquara & 16.864 \\
Marialva & 4.608 & Sarandi & 14.640 \\
Londrina & 2.772 & Cambé & 14.042 \\
Ibiporã & 2.032 & Fazenda Rio Grande & 12.099 \\
Campo Largo & 1.806 & Araucária & 9.070 \\
\hline Total & 63.276 & Total & 198.207 \\
\hline
\end{tabular}

FONTE: DESCHAMPS; CINTRA (2007) Adaptado

No Paraná, o que chama a atenção é que no ano de 2000, os municípios do Aglomerado Metropolitano de Curitiba foram os que mais se destacaram em relação ao maior número de saídas ${ }^{5}$. Pela Tabela 2, nos anos 1980, Londrina ainda se destacava entre os dez municípios com maiores fluxos de partida no Paraná. Em 2000, esse município já não aparece, mas destaca-se como um dos que mais recebem pendulares, com 24.824 pessoas. À sua frente estão Curitiba e Maringá, que em 2000 acolhem 167.496 e 28.871 pessoas, respectivamente (DESCHAMPS e CINTRA, 2007). 
Ainda quanto às saídas (2000), ao norte do Paraná aparece Sarandi (Região Metropolitana de Maringá) e mantém-se Cambé, na Região Metropolitana de Londrina. Como registram os autores acima, no Paraná, em 2000, os fluxos com mais de mil pessoas tiveram aumento significativo em relação aos anos 1980. Enquanto nesse último ano 15 municípios estavam representados, em 2000 cerca de 40 tinham mais de mil pessoas deslocando-se diariamente.

Desde 1970, no contexto dos municípios da RMC, Colombo tem apresentado uma das mais elevadas taxas de crescimento populacional. Dos 8.719 habitantes nos anos 1970, passou a 183.329 em 2000, com cerca de 96\% de urbanização. Essa elevada taxa de urbanização se concentra em alguns pontos do município, especificamente nos bairros localizados na divisa com Curitiba; em 1988, por exemplo, mais de $90 \%$ da população urbana do município de Colombo residia fora de sua sede administrativa (ULTRAMARI e MOURA, 1994). De certa forma, esse crescimento populacional pode ser expresso pelo número de lotes legais e ocupações irregulares. Segundo levantamento da COMEC (2006), entre os municípios do Núcleo Urbano de Curitiba, de 1940 a 2000, Colombo representou 15,15\% do total dos lotes aprovados, sendo superado somente por São José dos Pinhais, com $21 \%{ }^{6}$. Nas ocupações irregulares, em 1997 Colombo sediava 11,34\% da RMC, antecedido por Curitiba, que sozinha recebeu $34,40 \%$ das ocupações (COMEC, 1997) ${ }^{7}$. Em 2007, a contagem da população do IBGE revelou cerca de 233.916 habitantes residindo em Colombo, com uma das mais altas densidades demográficas da RMC (1.182,65 $\left.\mathrm{hab} / \mathrm{km}^{2}\right)$, perdendo apenas para Curitiba $\left(4.127,28 \mathrm{hab} / \mathrm{km}^{2}\right)$ (IPARDES, 2008). No período 1991-2000, destacou-se como um dos municípios da RMC com maiores taxas de crescimento anual, 5,09\% (IBGE, 2004) ${ }^{8}$. Entre 1995 e 2000, 95,7\% dos migrantes em Colombo provinham do próprio Paraná, seguido de São Paulo $(3,5 \%)$ e Mato Grosso do Sul (0,85\%). Do total considerado para o Paraná, $56 \%$ do fluxo provinha de Curitiba (11.073 pessoas), seguido por Pinhais $(1,121)$, Cerro Azul (673), São José dos Pinhais (602) e Almirante Tamandaré (511) (IBGE, 2000). Ou seja, dos migrantes que se dirigiram para Colombo, o maior volume vinha da própria capital e RMC, conformando uma migração intrametropolitana.

\section{Variáveis escalares explicativas do fluxo pendular de saída}

Para entender essa mobilidade originada da RMC para Colombo, seu expressivo crescimento demográfico e o destaque no deslocamento pendular paranaense, é preciso abrir um longo parêntese sobre a cidade de Curitiba. Esses dois lugares estão espacialmente conectados pela dinâmica de um fluxo populacional entre seus municípios, mas não se deve esquecer que o significativo fluxo imigratório ocorrido em Colombo desde o final dos anos 1970 se insere numa longa história de mobilidade espacial da população brasileira. Ou seja: o crescimento da 
ocupação urbana de Colombo e seu atual deslocamento pendular em direção a Curitiba se inscrevem numa história da própria mobilidade territorial brasileira, e da particularidade do planejamento urbano em Curitiba. Essa intercalação de escalas espaciais explicativas é fundamental para se entender o fluxo pendular. Mas, antes de entrar nesse viés analítico, atentemos para o relato de Carlos, 24 anos, morador de Colombo, do bairro Jardim Osasco.

O meu pai é mineiro, do norte de Minas Gerais. Aqui em Curitiba chegou ao final de 1970. Mas ele primeiro veio para o norte do Paraná, Barbosa Ferraz. Meu avô saiu pressionado de Minas (onde ele morava). Tinha um grande fazendeiro comprando todas as terras por lá e forçou o meu avô a vender suas terras: ou ele vendia ou ele vendia. Aí eles acabaram vindo pra cá. A família toda, os 13 filhos dele para o norte do Paraná. Depois de Barbosa, meu pai veio morar em Curitiba. Curitiba não, Pinhais. Veio morar com o tio dele em Pinhais e de Pinhais ele foi morar em Colombo, no final de 1980. E assim minha mãe também. Minha mãe, ela também não é curitibana, é alagoana. Meus pais se conheceram aqui. Meu pai conheceu minha mãe em Pinhais e de lá foram pra Colombo.

Essa transcrição abre pistas para conceber a mobilidade pendular como desdobramento de um múltiplo processo migratório intercalado por tempos bem distintos uns dos outros; o que coloca vários desafios teórico-metodológicos. 0 desafio essencial volta-se para uma reflexão escalar: as duas escalas "Origem" e "Destino" (tradicionais nos estudos migratórios de qualquer natureza) são insuficientes analiticamente. O recorte de análise, neste artigo, trata do deslocamento pendular de Colombo para Curitiba (2000) e, pelo relato, fica claro que a trajetória desse deslocamento se insere numa longa história, cujos efeitos despontam hoje em tal pendularidade, mas atravessados por dinâmicas temporais distintas, que se estenderam e se estendem no território brasileiro. Primeiro, nos anos de 1950, o norte e nordeste de Minas Gerais, região onde cada vez mais se expandiam as fazendas de gado, expulsando vaqueiros e agricultores para outras porções do país, mormente Paraná e São Paulo9.

Assim, o relato trata de um avô com 13 filhos, e dos membros da família contratados no noroeste paranaense para a colheita do café. Exaurida a produção cafeeira, no processo de modernização agrícola que deu lugar às extensas plantações de soja, migram para a periferia das metrópoles brasileiras. No Paraná, o fluxo converge para Curitiba que, nos anos 1970, entrava num projeto de modernização urbana e econômica, com demanda de trabalhadores na construção civil e em obras públicas de esgoto e saneamento.

Em paralelo a essa alteração paisagística, ocorre a implantação do sistema viário urbano ao longo das vias estruturais nos setores norte e sul de Curitiba. Segundo Tremarin (2001), as vias estruturais valorizaram os bairros ao norte de 
Curitiba, como Santa Cândida, Juvevê e Boa Vista, ocupados por uma classe de maior renda e poder aquisitivo elevado ${ }^{10}$. No oposto, na porção sul de Curitiba, políticas habitacionais para conjuntos populares direcionam uma ocupação urbana para uma população com menor poder aquisitivo e prestígio social. 0 uso da cartografia populacional mais uma vez é significativo para demonstrar essa desigualdade na repartição do espaço urbano: os bairros ao sul de Curitiba tiveram um crescimento demográfico vertiginoso, como é o caso de Sítio Cercado, que entre 1970 e 2000 cresceu cerca de $10.213 \%$, enquanto no mesmo período Boa Vista (porção norte) cresceu 89\%. Nesse contexto espacial, nos anos 1970 Curitiba tornou-se uma cidade cara demais para se habitar.

Da análise de diversos autores até aqui apresentados, infere-se que o processo de periferização de Curitiba abrange, além do conjunto de bairros distantes do centro, como o sul e o sudoeste, principalmente municípios limítrofes à capital, que têm assumido a função de absorver população de baixa renda, que mesmo ali trabalhando, não consegue morar na capital. Essa expansão da periferia pelo entorno foi induzida, entre outros fatores, pela falta de políticas habitacionais no interior da metrópole que atendesse às necessidades de moradia de uma população migrante de mais baixa renda, com investimentos dirigidos a atender não à demanda de uma população urbana em crescimento, mas a uma lógica especulativa imobiliária. $\mathrm{Na}$ ausência de políticas públicas de habitação aliadas ao eficaz planejamento urbano seletivo para moradia popular e implantação de um ordenamento viário, a periferia se expande para os municípios contíguos à metrópole. Sobre Colombo, Ultramari e Moura, em 1994, escreviam:

A sede de Colombo parece representar um crescimento
quase nulo, enquanto o processo de ocupação periférica
avança em sua direção. Isso ocorre mais por tal processo
acompanhar um sistema viário e suas diretrizes, e
uma infraestrutura já implantada, do que por buscar o
incipiente comércio e serviço disponível na sede (p.59).

Sete anos depois, em 2001, Tremarim anotaria sobre Colombo: "um município que apresenta pequena diversificação econômica, incapaz de empregar os trabalhadores, ou mesmo de fornecer-lhes opções de comércio e de serviços" (p.1376) (grifo meu).

Em síntese, na análise dos fluxos pendulares, o que está em jogo não é só a distância percorrida entre duas localidades (origem e destino), mas as múltiplas causas que levam ao deslocamento de parcela de uma população local para atender às demandas de trabalho em outro município. Isso carece de análise. Nesta seção, dediquei-me a apontar uma das causalidades desse fenômeno que merecem ser contempladas: i) na própria história da mobilidade territorial brasileira, a partir dos anos 1950; ii) pela desigual repartição do espaço na metrópole paranaense. 
Tais reflexões nos encaminham a entender uma das questões fundamentais que motivaram este artigo: qual o lugar reservado ao trabalhador-migrante pendular na economia urbana de Curitiba? Em que setores da economia urbana suas atividades laborais são requisitadas?

\section{0 trabalho pendular em Curitiba}

Entre os municípios da Região Metropolitana, Colombo chama a atenção pela modesta participação no rendimento físico. Em 2000, enquanto Araucária registrava $10,99 \%$ do VAF estadual, e São José, 5,41\%, Colombo participava com modesto $0,84 \%$ (COMEC, 2006). Com uma População Economicamente Ativa (PEA) de 86.257 pessoas, $15,6 \%$ estavam ocupadas, em Colombo, no setor industrial (extrativo e de transformação); $18 \%$ no Comércio, 13\% na Construção Civil e 12\% em Serviços Domésticos (IPARDES, 2008). Desse total da PEA, 35\% se dirigiu a 15 municípios da RMC, onde Curitiba, sozinha, recebeu 28.803 trabalhadores.

Figura 1 - Colombo: principais destinos do fluxo pendular para o trabalho $-2000$

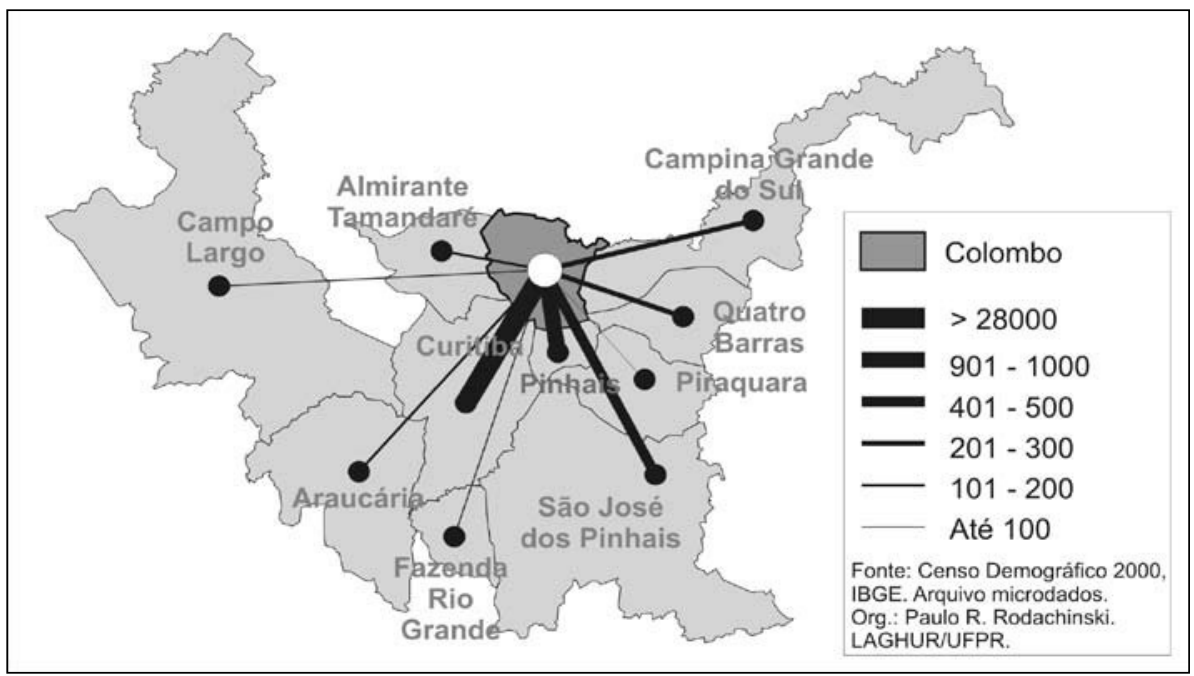

Como segundo destino, encontra-se Pinhais, onde 321 pessoas provindas de Colombo dedicam-se a atividades na Indústria de Transformação, 137 na Construção Civil e 132 no Comércio. Na sequência, São José dos Pinhais, com 106 ocupados na Indústria de Transformação, 94 na Construção Civil e 69 no Comércio. Chama a atenção Araucária, que, em relação aos dois municípios anteriores, exerce fraca atração, com 175 pessoas, das quais 34\% destinam-se para atividades na Indústria de Transformação (IBGE, Censo Demográfico 2000, arquivo microdados). 
Tabela 3 - principais grupos de atividades ocupadas pela população pendular de Colombo na RMC

\begin{tabular}{|c|c|c|}
\hline $\begin{array}{l}\text { GRUPOS DE } \\
\text { ATIVIDADES }\end{array}$ & $\begin{array}{c}\text { POPULAÇÃO } \\
\text { OCUPADA NA RMC }\end{array}$ & $\begin{array}{c}\text { POPULAÇÃO OCUPADA } \\
\text { EM CURITIBA }\end{array}$ \\
\hline Serviços domésticos & 4951 & 4913 \\
\hline Comércio & 4966 & 4636 \\
\hline Construção Civil & 4553 & 4167 \\
\hline Indústria de Transformação & 3370 & 2678 \\
\hline Atividades Imobiliárias & 2982 & 2843 \\
\hline TOTAL & 20822 & 19237 \\
\hline
\end{tabular}

FONTE: IBGE, Censo Demográfico 2000. Arquivo microdados.

Em conjunto, a figura 1 e a tabela 3 revelam uma organização do trabalho metropolitano que tem Curitiba como principal polo atrativo. Na divisão territorial do trabalho, Colombo tem cumprido o papel funcional de fornecer à RMC trabalhadores para serviços de baixa especialização e qualificação: a maior parte do fluxo pendular tem ocupação na RMC, particularmente o setor de Serviços Domésticos (IBGE, Censo 2000, Arquivo microdados).

Para esta seção, entrevistamos 15 pessoas que moram em diferentes municípios da Região Metropolitana e trabalham em Curitiba, no bairro Jardim Botânico. Nossas questões direcionaram-se mormente para o universo do trabalho, o tempo de deslocamento e os espaços de circulação quando se encontram em Curitiba. No bairro, são empregados no grupo de atividades designado Serviços Domésticos (diarista, empregada doméstica), nos setores de alimentação (cozinheiros e auxiliares de restaurante) e em Outros serviços (cabeleireira, manicura, porteiro de edifícios residenciais, atendente de balcão em pequenos mercados). Os (3) provenientes de Colombo gastam cerca de 90 minutos no trajeto de casa ao local de trabalho. No deslocamento completo (ida e volta) tomam 3 a 4 ônibus. Em Curitiba, permanecem longa parte do tempo diário, em média 11 horas. Pouco frequentam, como apontado anteriormente, a área central da sede de Colombo. Suas necessidades de consumo são supridas em Curitiba ou atendidas no comércio do bairro onde moram, e pouco circulam por Colombo. Também pouco usam os serviços de lazer da capital onde trabalham e não citam frequentar algum local comum de sociabilidade. $O$ que mais surpreende é que nenhum dos 15 entrevistados conhecia o cartão postal turístico da cidade de Curitiba, o Jardim Botânico, embora este se localize no mesmo bairro onde trabalham.

Bairro residencial, com aproximadamente 6.500 habitantes, o Jardim Botânico tem estabelecimentos comerciais pequenos, para atender à população local. 0 importante, nesse pequeno levantamento, é que nenhum dos 8 empregados em 10 estabelecimentos comerciais consultados, nem as 3 diaristas entrevistadas, nem os 4 porteiros de prédios residenciais, residiam no bairro. Dos 10 empregadores, 
somente 2 residem no bairro. ${ }^{11}$ Quanto aos 15 empregados, o grupo mais expressivo provém de Pinhais, seguido por Campo Largo e Colombo. Somente uma mulher provinha de Bocaiúva do Sul (para o serviço de empregada doméstica). Um grupo menor provinha de Curitiba, dos bairros Alto Boqueirão e Xaxim.

\section{O fluxo pendular da Região Metropolitana de Curitiba com destino a Colombo}

Em relação ao fluxo pendular, não se pode deixar de registrar que, enquanto Colombo enviava esse contingente de pessoas distribuídas pela RMC, recebia, ao mesmo tempo, cerca de 4.238 pessoas; 4.217 da própria Região Metropolitana e 21 do interior do Paraná.

Tabela 4 - fluxo pendular da RMC para Colombo: municípios e número de pessoas envolvidas (2000)

\begin{tabular}{|l|c|}
\hline \multicolumn{1}{|c|}{ ORIGEM } & NÚMERO DE PESSOAS \\
\hline Almirante Tamandaré & 390 \\
Araucária & 72 \\
Bocaiúva do Sul & 249 \\
Campina Grande do Sul & 478 \\
Campo Largo & 19 \\
Campo Magro & 18 \\
Cerro Azul & 13 \\
Curitiba & 1756 \\
Fazenda Rio Grande & 11 \\
Itaperuçu & 11 \\
Pinhais & 602 \\
Piraquara & 140 \\
Quatro Barras & 241 \\
Rio Branco do Sul & 32 \\
São José dos Pinhais & 185 \\
\hline Total & 4217 \\
\hline
\end{tabular}

FONTE: DESCHAMPS; CINTRA (2008)

O fluxo de Curitiba para Colombo tem suas particularidades: diferentemente do fluxo de Colombo, que abastece o polo da metrópole de servidores domésticos, do fluxo de Curitiba, $10 \%$ estão ocupados na educação, 6,5\% na fabricação de produtos metálicos e $4 \%$ no comércio de alimentos (IBGE 2000, Arquivo microdados). No bairro Alto Maracanã, em Colombo, como analisou Katzinsky (2004), existe um circuito produtivo preenchido por uma população provinda de 
Curitiba, como dentistas, técnicos e vendedores que atuam no setor da informática. Destinaram seus serviços para Colombo, em vista do alto custo para manter suas atividades em Curitiba.

O segundo maior fluxo para Colombo provém de Pinhais, onde 5,5\% da população pendular dedica-se às atividades no comércio de combustível, $5 \%$ na fabricação de produtos plásticos e $5 \%$ no transporte rodoviário. Em seguida, o fluxo originado de Campina Grande do Sul, do qual $24 \%$ das pessoas estão concentrados na fabricação de produtos metálicos e $9 \%$ na Construção Civil. É instigante que cada um desses municípios ocupe uma função específica no mercado de trabalho de Colombo. O fluxo de Itaperuçu e o de Fazenda Rio Grande apresentam também sua particularidade: todos os 11 pendulares de Itaperuçu estão ocupados na mesma atividade - fabricação de produtos metálicos; e os de Fazenda Rio Grande, todos os 11 ocupados no comércio de madeira ou material de construção (IBGE 2000, Arquivo microdados), o que pode indicar, mesmo considerando a baixa magnitude desse fluxo, uma rede de contratação no mercado de trabalho de Colombo. Essa mesma acepção de uma rede de trabalho é válida para os pendulares em Curitiba, pois segundo os entrevistados no Jardim Botânico, sua apresentação e a posterior contratação pelo empregador decorreram de indicação ("um conhecido chama o outro"). Em todas as entrevistas o pertencimento a uma rede social estava presente entre os pendulares: no trajeto da migração interna, no auxílio em mudanças de habitação entre a RMC, na inserção no mercado de trabalho urbano de Curitiba; enfim, são pistas metodológicas que se abrem para o prosseguimento de uma pesquisa sobre o movimento pendular.

Antes de terminar esta seção, é importante enfatizar que o migrante-pendular, com seus parcos recursos, taticamente constrói escalas de ação no território urbano. Para acompanhar o capital, habita as franjas da metrópole e no vai-e-vem diário, transportado nos apertados "ligeirinhos", símbolo do moderno transporte coletivo curitibano, insere-se formal ou informalmente nas brechas urbanas do mercado de trabalho metropolitano. Faxineira, zelador de prédio, vendedor ou atendente de caixa de supermercados ou dos mercadinhos; cozinheiro, ajudante de garçom, manicura, operador de telemarketing (para citar alguns dos ofícios dos pendulares) tecem uma identidade político-urbana ainda silenciosa e invisível. Essa nova cartografia populacional reconfigura o território urbano e, como sugere Massey (2008), nos instiga e convida a repensar o conceito de "lugar" e a refletir sobre uma metrópole onde um dos principais atores está à sua margem. Trata do deslocamento de trabalhadores para uma cidade que há muito já extrapolou seus limites de ocupação, o que obriga a colocar dentro de nossas reflexões teórico-metodológicas esse "outro", nada exótico e nem habitante de terras distantes. Esse "outro" está aqui: servidor doméstico, limpando as casas, servindo a mesa, dando o troco nas estações-tubo de passageiros e abrindo os portões dos edifícios, entre tantos outros ofícios. 
Trata-se de uma cidade que, em 2000, contava com 1.587.315 habitantes, aos quais se somavam 156.636 pessoas em fluxos pendulares, provindos dos diferentes municípios da RMC. Assim, até onde vai a Cidade de Curitiba? Até onde se estende Colombo? Pedaços urbanos aparentemente dispersos complementam-se numa lógica de ordenamento econômico que configura desigualdades espaciais e recria diferenças sociais. Nessa direção, o espaço metropolitano, sua configuração, análise e ação política tornam-se mais complexos.

\section{Considerações Finais}

É preciso esclarecer que, embora os dados temporais sobre o movimento pendular na Região Metropolitana de Curitiba limitem-se aos Censos Demográficos dos anos de 1980 e 2000 (o que inviabiliza uma análise em série histórica), procurei, para este artigo, desenvolver um instrumental metodológico que incorporasse ao ato do deslocamento pendular a idéia central de que esse tipo de fluxo se insere em um longo processo histórico. Para tal, na primeira seção, através de um relato, evidenciei que os fluxos se compõem de homens e mulheres que se deslocam, ao longo de gerações, em um movimento ininterrupto e inconcluso, decorrente de um processo marcado por modernizações produtivas regionais. De agricultores a trabalhadores urbanos, vão compondo essa trajetória coletiva da migração brasileira - ou seja, a pendularidade aqui tratada é fruto e efeito da modernização territorial, cujas raízes foram lançadas no Brasil há muitos anos.

Ressalto também que, nas abordagens da economia urbana neoclássica, a intensidade e direção do fluxo pendular servem como indicadores do grau, extensão e influência de uma cidade sobre outra, configurada numa dimensão bipolar: polos atrativos e polos repulsores de população; às vezes, em outras palavras, esses últimos são denominados "cidades-dormitório". Essa perspectiva funcional e dualista pode nos trazer a falsa idéia de que há sempre cidades disponíveis economicamente, abertas ao pioneirismo dos migrantes (internos, estrangeiros, sazonais, pendulares e outras tipologias). A pergunta deve ser redirecionada: mas atrativas para que serviços? Na segunda seção, através de um estudo de caso verifiquei que parcela significativa daqueles que compõem o fluxo pendular de Colombo para Curitiba estão empregados no setor de serviços domésticos urbanos, atividades estas que, na sociedade brasileira, não são as mais valoradas social e economicamente.

No Brasil, a partir dos anos 1970, as relações de trabalho passaram por profundas e radicais alterações. Ao mesmo tempo em que são geradas novas habilidades dependentes de um saber técnico, criam-se ou perpetuam-se antigas desigualdades sociais e econômicas. $\mathrm{O}$ mercado de trabalho torna-se mais segmentado, ainda que complementar: de um lado, o trabalho qualificado; 
de outro, o não-especializado. Assim, reiterando, provém de Colombo o grande número de servidores domésticos para RMC. Na lógica de um planejamento urbano seletivo, a desigualdade espacial é continente e conteúdo de uma desigual divisão territorial do trabalho.

As evidências aqui apresentadas reforçam a necessidade de um compromisso teórico-metodológico que considere o fluxo pendular como um movimento complexo, atravessado e motivado por múltiplas causalidades e recortes espaciais. Um olhar atento sobre a dinâmica e intensidade do fluxo pendular originado de Colombo em direção a Curitiba reforça também o compromisso de experimentarmos projetos políticos mais audaciosos, como o da gestão metropolitana. A experiência cotidiana de homens e mulheres que transitam entre várias unidades administrativas nos obriga a pensar em ações políticas solidárias entre os lugares e os habitantes citadinos.

\section{Notas}

1 - É preciso esclarecer que se trata de deslocamento pendular internacional e não da migração internacional. São tipologias distintas, e, para esta segunda, o quesito considerado, segundo o recenseamento do IBGE, é a mudança de residência. Para reforçar, o que caracteriza o deslocamento pendular é a saída diária do município de residência e o posterior retorno a ele. Vale registrar que o Paraná é o Estado brasileiro que concentra o maior número de pendulares internacionais: dos 51.955 brasileiros que se deslocaram para fora do país, 16.666 são provenientes do Paraná; seguido pelo Estado de São Paulo, com 7.959; e Rio Grande do Sul e Mato Grosso do Sul, 5.657 e 4.149 pessoas, respectivamente.

2 - Arquivo de Microdados (IBGE, Censo Demográfico 2000), organizado pelo Observatório das Metrópoles/Curitiba. Por disponibilizá-lo, agradeço a Marley Deschamps e Anael Cintra, integrantes do grupo.

3 - No primeiro semestre de 2008, entrevistamos 15 pessoas provenientes da RMC que trabalhavam em Curitiba e um estudante universitário, também em Curitiba. Foram entrevistas semiestruturadas, para as quais há um roteiro de questões elaboradas pelo pesquisador, e as demais informações são fruto da própria conversa. Nessas entrevistas, buscou-se enfatizar o espaço do trabalho desenvolvido na RMC. O número das entrevistas pode parecer pouco significativo; entretanto, trata-se de uma mobilidade em que os membros da família se deslocam diariamente. Todos os entrevistados conheciam diretamente, no mínimo, dez pessoas em semelhante movimento pendular.

4 - Disponível em: http://portal.rpc.com.br/gazetadopovo/vidaecidadania. Acesso em 12/09/2008. O Terminal do Alto Maracanã foi inaugurado em 1986 e é o principal nó da rede do transporte urbano coletivo em Colombo. Atualmente, partem dele: a Linha Direta - Ligeirinho Colombo-CIC; e os Alimentadores, ônibus que transportam usuários até aos terminais do Cabral, Santa Cândida e Capão da Imbuia, bairros localizados em Curitiba.

5 - Vinte e seis municípios integram a Região Metropolitana de Curitiba; entretanto, somente onze estão diretamente conectados a Curitiba, são eles: Almirante Tamandaré, Araucária, Campina Grande do Sul, Campo Largo, Campo Magro, Colombo, Fazenda Rio Grande, Pinhais, Piraquara, Quatro Barras e São José dos Pinhais. 
6 - Não foi possível comparar tais dados com os de Curitiba, pois, segundo a COMEC (2006, p.61), o município de Curitiba não possui um levantamento com o número de lotes aprovados.

7 - Em Curitiba, localizam-se 32.346 unidades de ocupação irregular; em Colombo, 6.274. (COMEC, 1997).

8 - Fazenda Rio Grande, 10,9\%; Piraquara, 9,92\%; e Almirante Tamandaré, 5,66\%. Curitiba, por sua vez, neste período $1991 / 2000$, teve $2,13 \%$ de taxa de crescimento. O que explicita que o crescimento populacional tem se dado nas bordas periféricas da metrópole.

9 - A migração de mineiros para o Estado do Paraná tem início nos anos de 1930. São migrantes provindos, sobretudo, dos vales do Mucuri e do Jequitinhonha, em Minas Gerais.

10 - Cabe aqui uma explicação: esses bairros, ao norte de Curitiba, localizam-se no limite geográfico com a área municipal de Colombo; ao longo desse limite, no lado de Colombo, há uma extensa faixa de ocupação urbana, com vários loteamentos legais e ocupações irregulares. É exatamente nesse pedaço do solo urbano que se verifica o maior adensamento populacional de Colombo.

11 - Consultamos dez estabelecimentos comerciais, como: salão de beleza, academia de ginástica, mercado, padaria, clínica odontológica, drogaria, restaurante, loja de cosméticos, pizzaria e videolocadora. O capital é local, a mão-de-obra um misto de familiares e contratados da RMC.

\section{Referências}

COMEC. Levantamento de ocupações irregulares na Região Metropolitana de Curitiba(1997). Curitiba, 1997.

COMEC. 2006. Plano de Desenvolvimento Integrado da Região Metropolitana de Curitiba: Propostas de Ordenamento Territorial e Novo Arranjo Institucional. Curitiba, 2006. CDROM.

DESCHAMPS, M.; CINTRA, A. Análise dos movimentos pendulares nos municípios da região metropolitana de Curitiba. In: V Encontro Nacional sobre Migrações.GT: Migração/ABEP, NEPO/UNICAMP, 2007.

DESCHAMPS, M.; CINTRA, A. Movimento pendular para trabalho na região metropolitana de Curitiba: uma análise das características de quem sai e quem fica. Anais XVI Encontro Nacional de Estudos Populacionais. ABEP, 2008. CD-ROM.

DIAS, L.C. Por que os bancos são o melhor negócio no país? In: ALBUQUERQUE, E. (Org.). Que país é esse? São Paulo: Ed. Globo, 2005, p.27-62.

FOUCAULT, M. Segurança, Território, População. São Paulo: Martins Fontes, 2008.

INSTITUTO BRASILEIRO DE GEOGRAFIA E ESTATÍSTICA. Tendências Demográficas: uma análise dos resultados da amostra do censo demográfico 2000. Rio de Janeiro: IBGE, 2004.

INSTITUTO BRASILEIRO DE GEOGRAFIA E ESTATístICA. Censo Demográfico 2000. (SIDRA). Disponível em: www.ibge.gov.br. Acesso em: agosto 2007.

IPARDES. CADERNO ESTATÍSTICO DO MUNICÍPIO DE COLOMBO. Disponível em: www.ipardes. gov.br. Acesso em: 12 set. 2008.

KATZINSKY, L. A análise da relação Colombo e Curitiba à luz da teoria dos dois circuitos da economia urbana. 2004. 96 f. Dissertação (Mestrado em Geografia) - Programa de PósGraduação em Geografia, Universidade Federal do Paraná, Curitiba, 2004. 
MASSEY, D. Pelo espaço: uma nova política da espacialidade. Trad. H. P. Maciel e R. Haesbaert. Rio de Janeiro: Bertrand Brasil, 2008. Título original: For Space.

POLANYI, K. A Grande Transformação: as origens da nossa época. Rio de Janeiro: Ed. Campus, 2000.

SANTOS, M. A Natureza do espaço: Técnica e Tempo. Razão e Emoção. São Paulo: Hucitec, 1996.

TREMARIN, A.R. Contradições de uma cidade planejada: análise do processo de ocupação e verticalização dos Setores Estruturais Norte e Sul de Curitiba. Anais IX ANPUR, vol. 3, 2001, p. $1370-81$.

ULTRAMARI, C.; MOURA, R. Grande Curitiba: teoria e prática. Curitiba: IPARDES, 1994.

\section{RESUMO}

Este artigo analisa o movimento pendular no aglomerado metropolitano de Curitiba. Metodologicamente, através dos dados censitários de 1980 e 2000, e do uso da entrevista semi-estruturada verifica-se um significativo trânsito cotidiano de uma população provinda de Colombo para trabalhar em Curitiba. Ao longo do texto, destaca-se que este fluxo pendular se insere em longo processo histórico, no qual homens e mulheres se deslocam, ao longo de gerações, em um movimento ininterrupto e inconcluso, decorrente de um processo marcado por modernizações produtivas regionais. Nos anos 1970, migrantes rurais para os centros urbanos; atualmente emergem como moradores da periferia metropolitana e empregados, em Curitiba, no setor de serviços domésticos urbanos. Conclui-se, neste vai-e-vem diário, que a escala metropolitana rompe os seus limites administrativos e políticos para a circulação do trabalhador mas, ao mesmo tempo, as cidades configuram-se por distintas funções econômicas, o que nos obriga a pensar em ações políticas solidárias entre os lugares e os habitantes citadinos.

Palavras-chave: migração intrametropolitana; aglomerado metropolitano de Curitiba, Colombo.

\section{ABSTRACT}

This paper analyzes commuter movements in the metropolitan agglomerate of Curitiba, Paraná. In methodological way, through the census data of 1980 and 2000 and semi-structured interviews, it is observed a significant daily movement of people from Colombo to Curitiba due to their working activities. Along the text it is stressed that these commuter flows interfer in long historical processes, where men and women move, along generations, in uninterrupted and unconclusive movements due to a process marked by regional productive modernization. In the 1970s, they were rural migrants for the urban centers, now they emerge as inhabitants of the metropolitan periphery and are employed in urban domestic services of Curitiba. It is concluded, through this daily come-and-go movement, that the metropolitan scale breaks its administrative and political limits for the worker's circulation but, at the same time, the cities are configured by different economic functions, what forces us to think in united political actions between places and city inhabitants.

Keywords: intrametropolitan migrations, metropolitan agglomerate of Curitiba, Colombo. 
